\title{
Estudo retrospectivo das neoplasias em ruminantes e equídeos no semiárido do Nordeste Brasileiro ${ }^{1}$
}

\author{
Fabricio K. de L. Carvalho² ${ }^{2}$, Antônio F.M. Dantas ${ }^{2 *}$, Franklin Riet-Correa ${ }^{2}$, Rachel L.F.S. \\ de Andrade ${ }^{2}$, Pedro I. da Nóbrega Neto ${ }^{2}$, Eldinê G. de Miranda Neto ${ }^{2}$, Sara V.D. Simões ${ }^{2}$ \\ e Sérgio S. Azevedo ${ }^{2}$
}

\begin{abstract}
Carvalho F.K.L., Dantas A.F.M., Riet-Correa F., Andrade R.L.F.S., Nóbrega Neto P.I., Miranda Neto E.G., Simões S.V.D. \& Azevedo S.S. 2014. [Retrospective study of tumors in ruminants and horses in semiarid Northeast of Brazil.] Estudo retrospectivo das neoplasias em ruminantes e equídeos no semiárido do Nordeste Brasileiro. Pesquisa Veterinária Brasileira 34(3):211-216. Hospital Veterinário, Laboratório de Patologia Animal, Centro de Saúde e Tecnologia Rural, Universidade Federal de Campina Grande, Campus de Patos, Avenida Universitária, s/n, Bairro Santa Cecília, Patos, PB 58708-110, Brazil. E-mail: dantas.af@uol.com.br

In Brazil, data related to occurrence of tumors in livestock are scarce. The objective of this study was to determine the frequency of tumors diagnosed in equidae, cattle, sheep and goats in the Pathology Laboratory of the Federal University of Campina Grande, Patos, state of Paraíba, from 1983 to 2010, and to analyze the risk factors by the chi square test, considering variables such as species, breed, age and sex. During the period, 177 (5.6\%) out of 3153 specimens from biopsies or necropsies were diagnosed as tumors. There were significant differences $(\mathrm{p}<0.001)$ in the frequency of tumors among different species; horses $(10.6 \%)$ were more affected than cattle $(6.8 \%)$, and cattle were more affected than goats $(3.3 \%)$ and sheep $(2.1 \%)$. Squamous cell carcinoma was most frequent tumor in cattle (58.3\% of the tumors), sheep (80\%) and goats (46.1\%), and sarcoid (45.3\%) was the most frequent in horses. Regarding the location, neoplasms were more common in the skin of horses (62.5\%) and sheep (60\%), in the eyes and periocular skin in cattle $(36.1 \%)$, and un the female reproductive system (perineal region and vulva) of goats (34.6\%). Regarding the sex of the animals, only cattle had significant prevalence $(\mathrm{p}<0.001)$. Regarding age only goats showed significant prevalence $(\mathrm{p}=0.015)$. There was no significant prevalence in any animal species in relation to race. We concluded that squamous cell carcinomas in ruminants and equine sarcoid are the most common tumors in livestock in the semiarid Brazilian Northeast, and the equidae were the most affected among the species studied.
\end{abstract}

INDEX TERMS: Tumors, neoplasms, squamous cell carcinoma, sarcoid, lymphosarcoma, melanoma. Euidae, ruminants.

RESUMO. No Brasil, dados relacionados com a ocorrência de neoplasias em ruminantes e equinos são escassos. Objetivou-se com este trabalho determinar a frequência de neo-

\footnotetext{
${ }^{1}$ Recebido em 19 de julho de 2013.

Aceito para publicação em 25 de fevereiro de 2014.

Parte da Dissertação de Mestrado do primeiro autor, Programa de Pós-Graduação em Medicina Veterinária, Universidade Federal de Campina Grande (UFCG), Patos, PB, Brasil.

${ }^{2}$ Hospital Veterinário, Centro de Saúde e Tecnologia Rural (CSTR), UFCG, Av. Universitária s/n, Bairro Santa Cecília,Patos, PB 58708-110. *Autor para correspondência: dantas.af@uol.com.br
}

plasias diagnosticadas em bovinos, caprinos, ovinos e equídeos no Laboratório de Patologia Animal da Universidade Federal de Campina Grande, Patos, Paraíba, durante o período de 1983 a 2010 e analisar os fatores de risco, mediante o teste de qui-quadrado, considerando como variáveis, espécie, raça, sexo e idade. Durante o período foram registrados 177 (5,6\%) tumores de um total de 3.153 diagnósticos provenientes de biópsias e necropsias. Houve diferenças significantes $(\mathrm{p}<0,001)$ na frequência de tumores entre as diferentes espécies sendo mais acometidos os equinos $(10,6 \%)$, seguidos pelos bovinos $(6,8 \%)$, caprinos $(3,3 \%)$ e ovinos 
$(2,1 \%)$. Os tumores mais frequentes foram o carcinoma células escamosas (CCE) nos bovinos (58,3\%), ovinos (80\%) e caprinos $(46,1 \%)$ e o sarcoide em equinos $(45,3 \%)$. Quanto à localização anatômica, as neoplasias foram mais frequentes na pele em equídeos $(62,5 \%)$ e ovinos (60\%), olho e tecido periocular em bovinos $(36,1 \%)$ e sistema reprodutor feminino (períneo e vulva) em caprinos $(34,6 \%)$. Em relação ao sexo dos animais, apenas os bovinos apresentaram prevalência significativa $(\mathrm{p}<0,001)$. Em relação à idade apenas os caprinos apresentaram prevalência significativa $(p=0,015)$. Não houve prevalência significativa em nenhuma espécie em relação à raça. Conclui-se que os carcinomas de células escamosas em ruminantes e o sarcoide em equídeos são os tumores mais frequentes em animais de produção no semiárido do Nordeste Brasileiro e que a espécie equina foi a mais acometida dentre as espécies estudadas.

TERMOS DE INDEXAÇÃO: Tumores, neoplasmas, carcinoma de células escamosas, sarcoide, linfossarcoma, melanoma. equídeos, ruminantes.

\section{INTRODUÇÃO}

As neoplasias em animais de produção determinam perdas econômicas em todas as regiões do Brasil, porém registros de levantamentos sobre a sua ocorrência são escassos (Ramos et al. 2008, Souza et al. 2011, Lucena et al. 2011). Em poucos estados do Brasil existem dados concretos sobre as neoplasias que acometem animais de produção, sendo grande parte das informações acerca de um tipo de neoplasia sob forma de relatos de casos específicos (Reis et al. 2002, Barros et al. 2006, Ramos et al. 2007, Barbosa et al. 2009, Brum et al. 2010).

Estudos retrospectivos de neoplasias são necessários para conhecer os dados clínicos e patológicos, além de aspectos epidemiológicos e comportamento biológico, podendo assim fornecer informações importantes referentes ao prognóstico, tratamento e prevenção.

Objetivou-se com este trabalho determinar a frequência de neoplasias ocorridas em bovinos, caprinos, ovinos e equídeos diagnosticados no Laboratório de Patologia Animal (LPA) da Universidade Federal de Campina Grande (UFCG), Campus de Patos, no período de 1983 a 2010, associando aspectos epidemiológicos à frequência destas neoplasias.

\section{MATERIAL E MÉTODOS}

Foram revisados os arquivos do LPA no período de 1983 a 2010, referentes a doenças neoplásicas diagnosticadas em bovinos, caprinos, ovinos e equídeos. Foram avaliadas informações referentes à espécie, raça, sexo e idade. Em relação à idade os ruminantes foram agrupados em jovens (até 2 anos), adultos (2 a 7 anos) e senis (acima de 7 anos). Já os equídeos, foram considerados animais jovens até 5 anos, animais adultos de 5 anos a 14 anos e senis acima de 14 anos.

Foi avaliada através do teste de qui-quadrado de aderência a ocorrência dos tumores por sistema acometido. Realizou-se a análise de fatores de risco em relação aos casos diagnosticados como neoplasias em um estudo caso controle, utilizando-se o teste de qui-quadrado, considerando como casos todos os animais com neoplasia e como controles o mesmo número de animais escolhidos ao acaso entre os animais encaminhados ao LPA por outras causas e isentos de neoplasia. As variáveis consideradas foram espécie, raça, sexo e idade. Informações que não constavam na ficha clínica foram excluídas da análise estatística.

Algumas lâminas antigas foram descoradas com ácido acético e coradas pela hematoxilina e eosina. Quando necessário, os materiais arquivados em blocos de parafina foram encaminhados para confecção de novas lâminas para classificação das neoplasias. Consideraram-se os diagnósticos morfológicos que constavam nos protocolos originais, buscando apenas quando necessário, a padronização dos mesmos com o sistema atual de classificação dos tipos histológicos, conforme preconizados pela Organização Mundial da Saúde (OMS) e peo livro texto clássico de neoplasias em animis domésticos classificação de (Meuten 2002).

\section{RESULTADOS}

De janeiro de 1983 a dezembro de 2010 foram examinados 3.153 materiais provenientes de biópsias e necropsias de ruminantes e equídeos. Desses, 177 (5,6\%) diagnósticos foram de neoplasias, sendo 127 malignas $(71,8 \%)$ e 50 benignas $(28,2 \%)$. A frequência de tumores em equinos foi significativamente maior $(\mathrm{P}=0,017)$ do que a observada em bovinos, caprinos $(\mathrm{p}<0,001)$ e ovinos $(\mathrm{p}<0,001)$, enquanto que a frequência em bovinos foi significativamente maior do que em caprinos $(\mathrm{p}=0,009)$ e ovinos $(\mathrm{p}<0,001)$ (Quadro 1 ).

Os dados referentes ao sistema ou órgão afetado relacionado por espécie animal encontram-se no Quadro 2. Os tumores de pele foram os mais frequentes em equídeos $(p=0,006)$ e ovinos $(p=0,018)$. Em bovinos a localização

Quadro 1. Frequência das neoplasias diagnosticadas em ruminantes e equídeos no LPA da UFCG durante o período de 1983 a 2010, Patos, Paraíba

\begin{tabular}{lcc}
\hline Espécies & Total de animais & Neoplasias (\%) \\
\hline Bovinos (B) & 1052 & $72(6,8 \%)$ \\
Equídeos (E) & 603 & $64(10,6 \%)$ \\
Caprinos (C) & 709 & $26(3,3 \%)$ \\
Ovinos (O) & 789 & $15(2,1 \%)$ \\
TOTAL & 3.153 & $177(5,6 \%)$ \\
P $^{a}$ & $<0,001^{*}$ &
\end{tabular}

a Probabilidade (teste de qui-quadrado de aderência); * Probabilidade $2 x 2$ : BxE $(p=0,017) ; \operatorname{BxC}(p=0,009) ; \operatorname{BxO}(p<0,001) ; \operatorname{ExC}(p<0,001) ; \operatorname{ExO}$ $(\mathrm{p}<0,001) ; \mathrm{CxO}(\mathrm{p}=0,06)$.

Quadro 2. Número de neoplasias distribuídas de acordo com a espécie animal e sistema afetado diagnosticadas no LPA da UFCG durante o período de 1983 a 2010, Patos, Paraíba

\begin{tabular}{lccccc}
\hline Sistema afetado & Bovinos & Equídeos & Caprinos & Ovinos & Total \\
\hline Pele e tecido subcutâneo & 17 & 40 & 5 & 9 & 71 \\
Olho e tecido periocular & 26 & 7 & 2 & 3 & 38 \\
Reprodutor feminino & 9 & 4 & 9 & & 22 \\
Hematopoiético & 10 & 1 & 2 & & 13 \\
Reprodutor masculino & 1 & 7 & 3 & & 11 \\
Respiratório & 3 & & & & 3 \\
Musculoesquelético & & & 3 & & 3 \\
Fígado e pâncreas & 2 & & 1 & & 3 \\
Digestório & 1 & 1 & & & 2 \\
Nervoso & 1 & & & & 2 \\
Endócrino & 1 & & & 1 & 1 \\
Não informado & 1 & 4 & 64 & 15 & 177 \\
TOTAL & 72 & 64 & 26 & 018 & \\
Pa & $<0,001$ & 0,006 & $<0,001$ & 0,018
\end{tabular}

$\bar{a}$ Probabilidade (teste de qui-quadrado de aderência). 


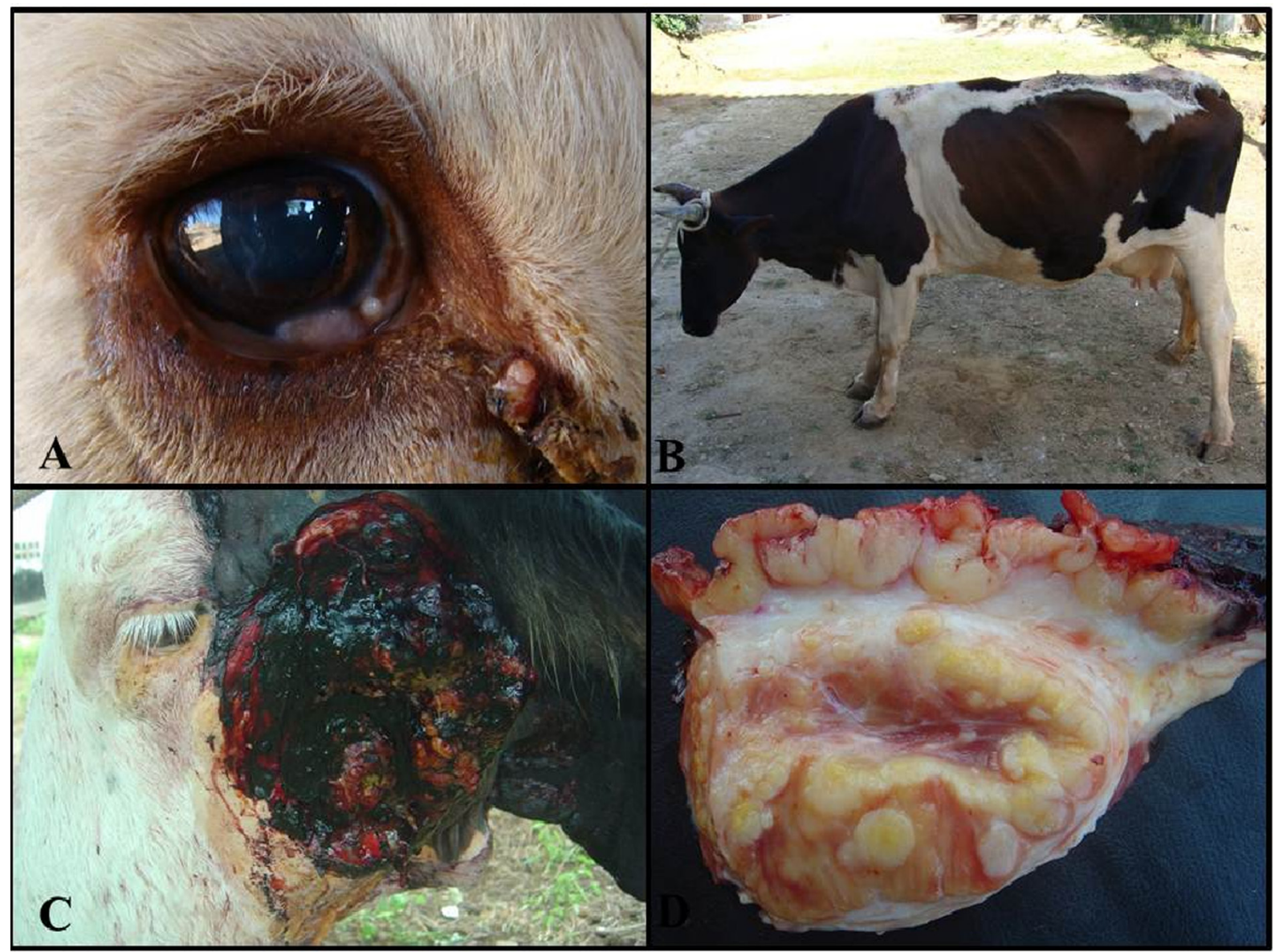

Fig.1. Carcinoma de células escamosas (CCE) em bovinos. (A) Fase inicial do CCE no olho. (B) CCE na pele da região dorsal de bovino mestiço de holandês. (C) CCE na pele da cabeça. (D) CCE na pele com metástase no linfonodo parotídeo.

mais frequente $(p<0,001)$ foi no olho e tecido periocular, enquanto que em caprinos foi no sistema reprodutor feminino (vulva e períneo) $(\mathrm{p}<0,001)$. Considerando todas as espécies o sistema tegumentar foi o mais acometido (71 casos), seguido de olho e tecido periocular (38 casos), reprodutor feminino (22 casos), hematopoiético (13 casos) e reprodutor masculino (11 casos).

Os principais tumores diagnosticados entre todas as espécies foram carcinoma de células escamosas (CCE) (81casos) (Fig.1), sarcoide equino (29 casos) (Fig.2), linfossarcoma (13 casos), fibrossarcoma (12 casos) e melanoma (10 casos) (Fig.2). Outros tipos de neoplasias ocorreram menos frequentemente ou de forma esporádica e encontram-se no Quadro 3.

O CCE foi observado principalmente em bovinos (42 casos), seguida de equinos (15 casos), caprinos (12 casos) e 12 casos em ovinos. Dos 29 casos de sarcoide, 22 ocorreram em equinos, envolvendo principalmente a pele da região da cabeça e membros, seis casos em asininos e um em muar. Dos 13 casos de linfossarcoma, sete eram de leucose enzoótica e três de leucose juvenil (esporádica), além de dois casos em caprinos e um em equino (multicêntrico). Dos 12 casos de fibrossarcomas, seis ocorreram em equídeos, sendo quatro na pele (dois equinos, um asinino e um muar), um no prepúcio e outro na vulva de equinos. Dos 10 casos de mela- nomas, sete ocorreram na pele, sendo quatro casos em equinos, dois em caprinos e um bovino, além de três casos na vulva de cabras. Outros tipos de neoplasias ocorreram menos frequentemente ou de forma esporádica e encontram-se no Quadro 3. Os dados referentes à raça, sexo e idade das espécies estudadas são observados nos Quadros 4 e 5.

Nos bovinos, a região mais afetada foi o olho e tecido periocular, sendo 25 carcinomas de células escamosas e um fibroma. Dos 18 casos de tumores na pele, 10 foram CCEs. Outros tipos de tumores encontram-se distribuídos no Quadro 3, de acordo com o sistema afetado e sua frequência. Em relação ao sexo, as fêmeas (56/72) apresentaram diferença significativa em relação aos machos (14/72) $(p<0,001)$. Em dois casos o sexo não foi informado. Não foram encontradas diferenças significativas em relação a idade $(p=0,520)$ e a raça $(p=0,127)$ dos animais afetados.

Em caprinos, a localização mais frequente foi no sistema reprodutor feminino $(\mathrm{p}<0,001)$, sendo seis casos CCE e três melanomas. Cinco casos foram diagnosticados na pele. A maioria dos casos (20/26) foi observada em cabras adultas $(p=0,015)$, quatro casos foram em cabras idosas. Não houve diferenças significativas na frequência de tumores em relação a raça $(p=0,421)$ e sexo $(p=0,103)$.

Nos ovinos, a localização mais frequente de tumores $(p=0,018)$ foi a pele (nove casos), sendo sete CCE, um mi- 


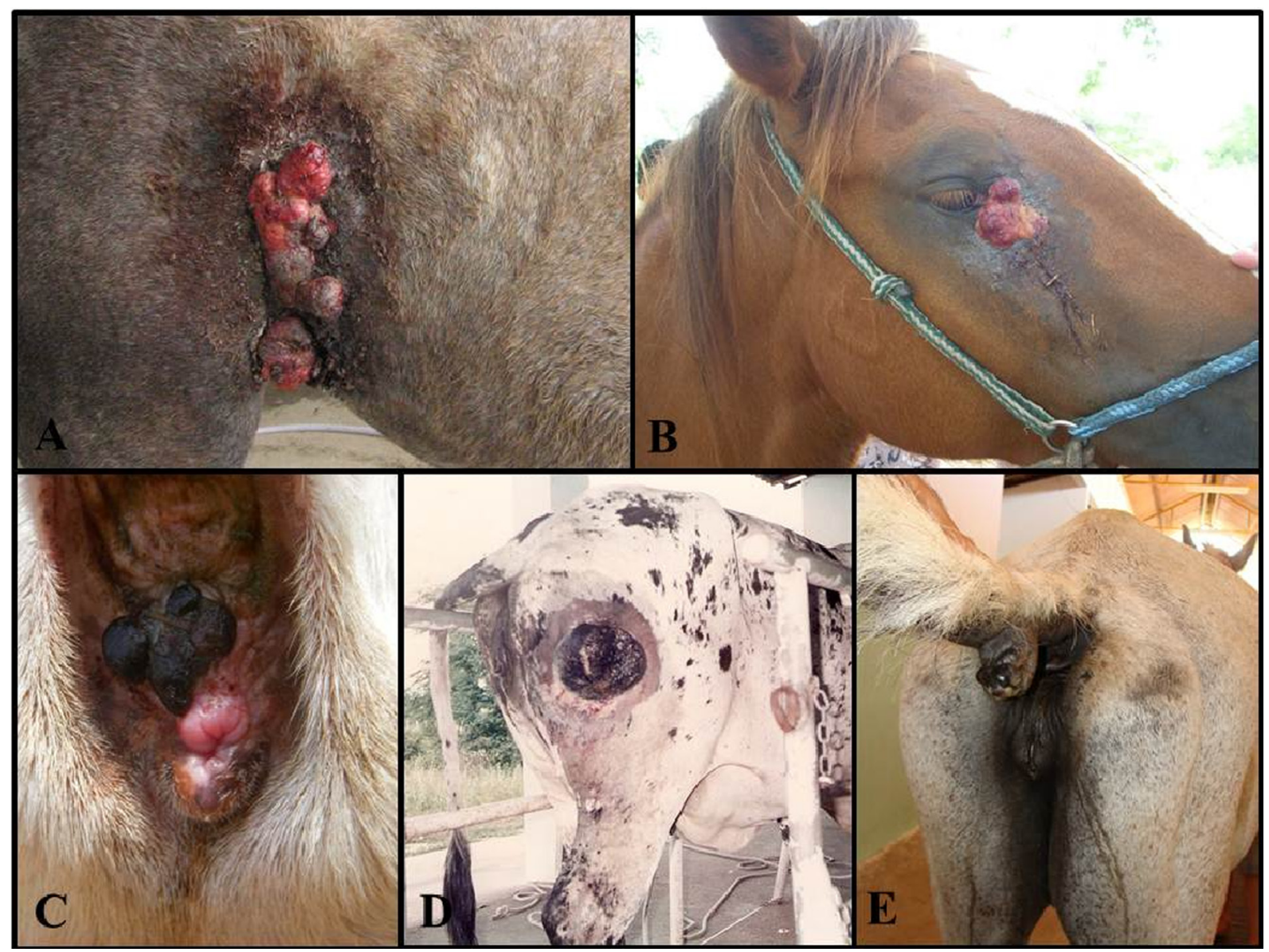

Fig.2. (A) Sarcoide equino na região do flanco direito e (B) na região da pele da região periorbital. (C) Cabra com melanoma na região perineal. (D) Bovino com melanoma na pele do membro posterior direito (face lateral direita). (E) Equino com melanoma na base da cauda.

xoma e um hemangioma. Três casos de CCE estavam localizados no olho e em outros dois casos, a região afetada não tinha sido informada. Um caso de meduloblastoma foi diagnosticado no cerebelo e tronco encefálico. Não foram encontradas diferenças significantes na frequência de tumores entre raças $(\mathrm{p}=0,443)$, idade $(\mathrm{p}=0,467)$ e sexo $(\mathrm{p}=0,770)$, apesar do maior número de casos terem sido diagnosticados em fêmeas $(12 / 15)$.

Nos equídeos, o sistema tegumentar foi significativamente mais afetado $(\mathrm{p}=0,006)$, correspondendo a 40 casos $(62,5 \%)$. Uma parcela significativa está ligada ao número de sarcoide (22 casos) diagnosticados nesta região, deste total cinco foram diagnosticados em asininos. Outros tumores frequentes foram melanoma, fibrossarcoma e CCE (quatro casos cada) e três casos de fibroma. Os demais tumores encontram-se distribuídos no Quadro 3, de acordo com o sistema afetado e sua frequência. Não foram observadas diferenças significativas na frequência de tumores entre raças $(p=0,665)$, sexo $(p=0,801)$ e idade $(p=0,566)$.

\section{DISCUSSÃO}

Os equídeos $(10,6 \%)$ e os bovinos $(6,8 \%)$ foram as espécies mais acometidas. Resultados semelhantes foram encontrados no Brasil (Ramos et al. 2008) e em outros países (Plummer 1948, Plummer 1956, Misdorp 1967, Priester \& Mantel
1971). A alta frequência de sarcoide equino elevou o número de ocorrências de tumores nos equídeos. Essa neoplasia é considerada a mais prevalente na espécie equina (Scott e Miller Jr., 2011), podendo chegar a 60\% em relação a outros tumores (Valentine 2006, Rooney \& Robertson 1996). Esta neoplasia é também a mais observada em equinos no Rio Grande do Sul, variando de 57,4\% (Souza et al. 2011) a 43,1\% (Ramos et al. 2008) dos tumores diagnosticados. 0 sarcoide equino está associado ao papilomavírus bovino (BPV) tipos 1 e 2 (Nasir \& Campo 2008, Scott \& Miller Jr 2011). Recentemente foi confirmado no Brasil a ocorrência de sarcoide equino associado à infecção pelo BPV BR-UEL-4 (Anjos et al. 2010), que possui grande similaridade com o BPV-2 isolado em sarcoide equino, também no Brasil (Nasir \& Campo 2008).

Em bovinos observou-se, também, uma alta frequência de tumores, devido à alta ocorrência de CCE com localização no olho e tecido periocular, pele e sistema reprodutor feminino, todos eles associados às radiações solares que no semiárido do nordeste são intensas durante todo o ano. Outro fator que pode estar associado a esta alta frequência de CCE é a presença na região de vacas adultas da raça Holandesa ou suas cruzas, incluindo a Girolando. As raças Holandesa e Hereford são consideradas mais susceptíveis a estes tumores do que outras raças (Tsujita \& Plummer 
2010). 0 linfossarcoma foi o segundo tumor mais frequente em bovinos. Na Paraíba, a frequência de bovinos leiteiros com anticorpos da leucose foi de 8,3\% (Simões 1998). A frequência de bovinos com linfossarcoma $(1,05 \%)$ em relação ao total das doenças diagnosticadas é semelhante às encontradas em outros trabalhos no Brasil por Silva Filho et al. (2011), Ramos et al. (2008) e Lucena et al. (2011) e onde observaram frequências de $0,5 \%, 0,6 \%$ e $1,5 \%$, respectivamente.

Quadro 3. Tipos de neoplasias relacionando o sistema afetado, tipo de tumor e espécie animal diagnosticadas no LPA da UFCG durante o período de 1983 a 2010, Patos, Paraíba.

Sistema afetado Tipos de tumores Bovino Equídeo Caprino Ovino Tota

\begin{tabular}{|c|c|c|c|c|c|c|}
\hline Pele e tecido & $\begin{array}{l}\text { Carcinoma de cé- } \\
\text { lulas escamosas }\end{array}$ & 10 & 4 & 1 & 7 & 22 \\
\hline \multirow[t]{10}{*}{ Subcutâneo } & Sarcoide & & 22 & & & 22 \\
\hline & Fibrossarcoma & 1 & 4 & 2 & & 7 \\
\hline & Melanoma & 1 & 4 & 2 & & 7 \\
\hline & Papiloma & 3 & 1 & & & 4 \\
\hline & Fibroma & & 3 & & & 3 \\
\hline & Mixoma & 1 & & & 1 & 2 \\
\hline & Hemangioma & & & & 1 & 1 \\
\hline & Hemangioperocitoma & & 1 & & & 1 \\
\hline & Fibro-histiocitoma & & 1 & & & 1 \\
\hline & Fibropapiloma & 1 & & & & 1 \\
\hline Olho e tecido & $\begin{array}{l}\text { Carcinoma de cé- } \\
\text { lulas escamosas }\end{array}$ & 25 & 5 & 2 & 3 & 35 \\
\hline \multirow[t]{3}{*}{ Periocular } & Adenocarcinoma & & 1 & & & 1 \\
\hline & Fibroma & 1 & & & & 1 \\
\hline & Sarcoide & & 1 & & & 1 \\
\hline $\begin{array}{l}14 \text { Hemato- } \\
\text { poiético }\end{array}$ & Linfossarcoma & 10 & 1 & 2 & & 13 \\
\hline \multirow[t]{2}{*}{ Digestório } & Ameloblastoma & & 1 & & & 1 \\
\hline & Fibrossarcoma & 1 & & & & 1 \\
\hline \multirow[t]{2}{*}{ Respiratório } & Fibrossarcoma & 2 & & & & 2 \\
\hline & Mixoma & 1 & & & & 1 \\
\hline Reprodutor & $\begin{array}{l}\text { Carcinoma de cé- } \\
\text { lulas escamosas }\end{array}$ & & 3 & 2 & & 5 \\
\hline \multirow[t]{5}{*}{ masculino } & Sarcoide & & 2 & & & 2 \\
\hline & Fibropapiloma & 1 & & & & 1 \\
\hline & Fibrossarcoma & & 1 & & & 1 \\
\hline & Papiloma & & 1 & & & 1 \\
\hline & Fibroma & & & 1 & & 1 \\
\hline \multirow[t]{7}{*}{$\begin{array}{l}\text { Reprodutor } \\
\text { feminino }\end{array}$} & $\begin{array}{l}\text { Carcinoma de cé- } \\
\text { lulas escamosas }\end{array}$ & 6 & 1 & 6 & & 13 \\
\hline & Melanoma & & & 3 & & 3 \\
\hline & Sarcoide & & 2 & & & 2 \\
\hline & Hemangiossarcoma & 1 & & & & 1 \\
\hline & Fibrossarcoma & & 1 & & & 1 \\
\hline & Teratoma & 1 & & & & 1 \\
\hline & Fibropapiloma & 1 & & & & 1 \\
\hline Endócrino & Feocromocitoma & 1 & & & & 1 \\
\hline \multirow[t]{2}{*}{ Nervoso } & Meduloblastoma & & & & 1 & 1 \\
\hline & Meningioma & 1 & & & & 1 \\
\hline \multirow{3}{*}{$\begin{array}{l}\text { Musculoes- } \\
\text { quelético }\end{array}$} & Condorssarcoma & & & 1 & & 1 \\
\hline & Osteossarcoma & & & 1 & & 1 \\
\hline & Rabdomiossarcoma & & & 1 & & 1 \\
\hline \multirow{3}{*}{$\begin{array}{l}\text { Fígado e } \\
\text { pâncreas }\end{array}$} & Colangiossarcoma & & & 1 & & 1 \\
\hline & Carcinoma de pâncreas & 1 & & & & 1 \\
\hline & Hepatoma & 1 & & & & 1 \\
\hline \multirow[t]{2}{*}{ Não informado } & $\begin{array}{l}\text { Carcinoma de cé } \\
\text { lulas escamosas }\end{array}$ & 1 & 2 & 1 & 2 & 6 \\
\hline & Sarcoide & & 2 & & & 2 \\
\hline TOTAL GERAL & & 72 & 64 & 26 & 15 & 177 \\
\hline
\end{tabular}

Quadro 4. Número de neoplasias distribuídas por raça e espécie animal diagnosticadas no LPA da UFCG durante o período de 1983 a 2010, Patos, Paraíba

\begin{tabular}{|c|c|c|c|c|c|c|c|}
\hline \multicolumn{2}{|l|}{ Bovinos } & \multicolumn{2}{|l|}{ Equídeos } & \multicolumn{2}{|c|}{ Caprinos } & \multicolumn{2}{|c|}{ Ovinos } \\
\hline Raça & № & Raça & № & Raça & № & Raça & № \\
\hline Holandesa & 20 & Quarto de Milha & 17 & Saanen & 3 & Santa Inês & 5 \\
\hline Girolando & 2 & Asinino & 11 & Anglo & 3 & $\mathrm{SRD}^{\mathrm{a}}$ & 7 \\
\hline Pardo Suíço & 01 & Muar & 2 & Boer & 2 & & \\
\hline \multirow[t]{4}{*}{$\mathrm{SRD}^{\mathrm{a}}$} & 42 & Apalooza & 1 & Moxotó & 1 & & \\
\hline & & PaintHorse & 1 & Alpina & 1 & & \\
\hline & & Manga Larga & 1 & Togemburgo & o 1 & & \\
\hline & & $\mathrm{SRD}^{\mathrm{a}}$ & 26 & $\mathrm{SRD}^{\mathrm{a}}$ & 12 & & \\
\hline $\mathrm{Ni}^{\mathrm{b}}$ & 7 & $\mathrm{Ni}^{\mathrm{b}}$ & 5 & $\mathrm{Ni}^{\mathrm{b}}$ & 3 & $\mathrm{Ni}^{\mathrm{b}}$ & 3 \\
\hline TOTAL & 72 & Total & 64 & Total & 26 & Total & 15 \\
\hline $\mathrm{P}^{\mathrm{c}}$ & 0,127 & $\mathrm{P}^{\mathrm{c}}$ & 0,665 & $\mathrm{P}^{\mathrm{c}}$ & 0,461 & $\mathrm{P}^{\mathrm{c}}$ & 0,443 \\
\hline
\end{tabular}

a Sem raça definida; ${ }^{\mathrm{b}}$ Não informado; ${ }^{\text {cProbabilidade (teste de qui-qua- }}$ drado).

Quadro 5. Número de neoplasias distribuídas por sexo, idade e espécie animal diagnosticadas no LPA da UFCG durante o período de 1983 a 2010, Patos, Paraíba.

\begin{tabular}{lccccc}
\hline & Bovinos & Equídeos & Caprinos & Ovinos & Total \\
\hline Sexo & & & & & \\
Fêmea & 56 & 24 & 19 & 12 & 111 \\
Macho & 14 & 37 & 6 & 1 & 58 \\
Nia & 2 & 3 & 1 & 2 & 9 \\
$\mathrm{P}^{\mathrm{b}}$ & 0,001 & 0,801 & 0,103 & 0,770 &
\end{tabular}

Idade $-0,001-0,80$

$\begin{array}{llllll}\text { Jovem } & 7 & 31 & - & 4 & 42\end{array}$

$\begin{array}{llllll}\text { Adulto } & 43 & 21 & 20 & 6 & 90\end{array}$

$\begin{array}{llllll}\text { Senil } & 16 & 5 & 4 & 1 & 26\end{array}$

$\begin{array}{llllll}\mathrm{Ni}^{\mathrm{a}} & 6 & 7 & 2 & 4 & 20\end{array}$

$\begin{array}{lccccc}\mathrm{P}^{\mathrm{b}} & 0,520 & 0,566 & 0,015 & 0,467 & \\ \text { TOTAL } & 72 & 64 & 26 & 15 & 177\end{array}$

$\overline{{ }^{\mathrm{a}} \text { Não informado; }}{ }^{\mathrm{b}}$ Probabilidade (teste de qui-quadrado).

A frequência de tumores em caprinos e ovinos foi menor do que em equídeos e bovinos, sendo a pele em ovinos e o sistema reprodutor feminino em caprinos os sistemas mais acometidos. Desses, a maioria foi CCE, como também melanomas em caprinos. No Brasil, casos de CEE na pele (orelha e focinho) são frequentes em ovinos de raças de pele despigmentada e no períneo de caprinos das raças Saanen e Boer (Macêdo et al. 2008). Chama a atenção a alta frequência de melanomas em caprinos, o que pode ocorrer pelas intensas radiações solares durante todo o ano no Nordeste. Este tumor é de ocorrência comum em equinos, principalmente em animais idosos e de coloração acinzentada, porém é raro em outras espécies (Radostitis et al. 2002). As causas dessa neoplasia ainda não são bem descritas em caprinos, mas tem sido associado à idade avançada e animais que apresentam pele escura e afeta mais áreas desprovidas de pêlos como vulva, ânus, lábios narinas, orelhas e pálpebras (Madewell \& Theilen 1987, Ramadan et al. 1988).

\section{CONCLUSÃO}

Conclui-se que os Carcinomas de células escamosas (CCEs) em ruminantes e o sarcoide em equídeos são os tumores mais frequentes em animais de produção no semiárido do Nordeste Brasileiro, sendo a espécie equina a mais acometida por tumores. 
Agradecimentos.- À Coordenação de Aperfeiçoamento de Pessoal de Nível Superior (CAPES), pela concessão da bolsa durante o curso de Pós-Graduação.

\section{REFERÊNCIAS}

Anjos B.L., Silva M.S., Diefenbach A. Brito M.F., Seppa G.S. \& Brum M.C.S. 2010. Sarcoide equino associado ao papilomavírus bovino BR-UEL-4. Ciência Rural 40(6):1456-1459.

Barbosa J.D., Duarte M.D., Oliveira C.M.C., Reis A.B., Peixoto T.C., Peixoto P.V. \& Brito M.F. 2009. Carcinoma de células escamosas perineal em cabras no Pará. Pesq. Vet. Bras., 29(5):421-427.

Barros R.R., Rech R.R., Viott A.M. \& Barros C.S.L. 2006. Carcinoma de células escamosas no olho de bovino com invasão cerebral através dos nervos cranianos. Ciência Rural 36(5):1651-1654.

Brum J.S., Souza T.M. \& Barros C.S.L. 2010. Aspectos epidemiológicos e distribuição anatômica das diferentes formas clínicas do sarcoide equino no Rio Grande do Sul: 40 casos. Pesq. Vet. Bras. 30(10):839-843.

Lucena R.B., Rissi D.R., Kommers G.D., Pierezan F., Oliveira-Filho J.C., Macêdo J.T.S.A., Flores M.M. \& Barros C.S.L. 2011. A retrospective study of 586 tumours in Brazilian cattle. J. Comp. Pathol. 145:20-24.

Macêdo J.S.A., Riet-Correa F., Dantas A.F.M. \& Simões S.V.D. 2008. Doenças da pele em caprinos e ovinos no semiárido brasileiro. Pesq. Vet. Bras. 28(12):633-642.

Madewell B.R. \& Theilen G.H. 1987. Mast cell and melanocytic neoplasms, p.315-322. In: Ibid. (Eds), Veterinary Cancer Medicine. $2^{\text {nd }}$ ed. Lea and Febiger, Philadelphia.

Meuten D.J. 2002. Tumors in Domestic Animals. $4^{\text {th }}$ ed. Iowa State Press, Ames, p.45-118.

Misdorp W. 1967. Tumours in large domestic animals in the Netherlands. J. Comp. Pathol. 77:211-216.

Nasir L. \& Campo M.S. 2008. Bovine papillomaviruses: their role in the aetiology of cutaneous tumours of bovids and equids. Journal Compilation 9:243-254. Disponível em <http://www3.interscience.wiley.com/journal/121372333/abstract? cretry=1\&sretry=0 > Acessado em 15 jan. 2012.

Plummer P.J.G.A. 1948. Survey of twenty-four tumours collected from animals slaughtered for food. Can. J. Comp. Med. 12(7):180-186.
Plummer P.J.G. 1956. A survey of six hundred and thirty six tumours from domesticated animals. Can. J. Comp. Med. 20(7):239-251.

Priester W.A. \& Mantel N. 1971. Occurrence of tumors in domestic animals. Data from 12 United States and Canadian Colleges of Veterinary Medicine. J. Natl Cancer Inst. 47:1333-1344.

Radostits O.M., Gay C.C., Hinchcliff K.W. \& Constable P.D. 2002. Clínica Veterinária: um tratado de doenças dos bovinos, ovinos, suínos, caprinos e eqüinos. 9a ed. Guanabara Koogan, Rio de Janeiro. 1737p.

Ramadan R.O., El Hassan A.M. \& Taj El Deen M.H. 1988. Malignant melanoma in goats: a clinico-pathological study. J. Comp. Pathol. 98:237246.

Ramos A.T., Norte D.M., Elias F. \& Fernandes C.G. 2007. Carcinoma de células escamosas em bovinos, ovinos e equinos: estudo de 50 casos no sul do Rio Grande do Sul. Braz. J. Vet. Res. Anim. Sci. 44(Supl.):5-13.

Ramos A.T., Souza A.B., Norte D.M., Ferreira J.L.M. \& Fernandes C.G. 2008. Tumores em animais de produção: aspectos comparativos. Ciência Rural 38(1):148-154.

Reis D.O., Hortêncio M.C., Almeida L.P. \& Moreira M.D. 2002. Linfoma em bovinos abatidos sob inspeção federal: aspectos morfológicos e linfonodos mais acometidos. Biosci. J. 18(2):109-112.

Rooney J.R. \& Robertson J.L. 1996. Equine Pathology. Iowa State University Press, Ames, p.287-307.

Scott D.W. \& Miller Jr W.H. 2011. Equine Dermatology. $2^{\text {nd }}$ ed. Elsevier Saunders, Missouri, p.468-516.

Silva Filho A.P., Afonso J.A.B., Souza J.C.A., Riet-Correa F., Dantas A.F.M., Dantas A.C., Costa N.A.C. \& Mendonça C.L. 2011. Linfossarcoma em bovinos no agreste meridional de Pernambuco. Pesq. Vet. Bras. 31(7):591597.

Souza T.M., Brum J.S., Fighera R.A., Brass K.E. \& Barros C.S.L. 2011. Prevalência dos tumores cutâneos de equinos diagnosticados no Laboratório de Patologia Veterinária da Universidade Federal de Santa Maria, Rio Grande do Sul. Pesq. Vet. Bras. 31(5):379-382.

Tsujita H. \& Plummer C.E. 2010. Bovine ocular squamous cell carcinoma. Vet. Clin. North Am., Food Anim. Pract. 26:511-529.

Valentine B.A. 2006. Survey of equine cutaneous neoplasia in the Pacific Northwest. J. Vet. Diagn. Invest. 18:123-126. 